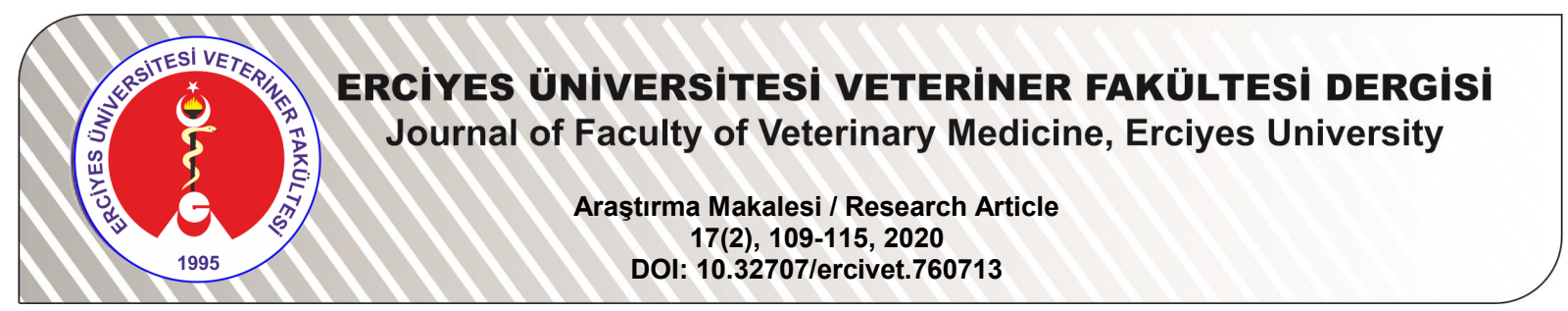

\title{
Kedilerde Medetomidin-Ketamin ve Zolazepam-Tiletamin Anestezilerinin Hematolojik ve Biyokimyasal Parametreler Üzerine Etkilerinin Karşılaştırılması
}

\author{
Nusret APAYDIN ${ }^{1}$, Musa AYDINGÜLER ${ }^{2}$ \\ ${ }^{1}$ Erciyes Üniversitesi, Veteriner Fakültesi Cerrahi Anabilim Dalı, Kayseri-TÜRKIYE \\ ${ }^{2}$ Erciyes Üniversitesi, Sağlık Bilimleri Enstitüsü, Kayseri-TÜRKIYE
}

Sorumlu yazar: Nusret APAYDIN; E-posta: nusretapaydin@gmail.com; ORCiD: 0000-0003-0447-1216

Atıf yapmak için: Apaydin N, Aydıngüler M. Kedilerde medetomidin-ketamin ve zolazepam-tiletamin anestezilerinin hematolojik ve biyokimyasal parametreler üzerine etkilerinin karşılaştırılması. Erciyes Üniv Vet Fak Derg 2020; 17(2): 109-115.

Özet: Bu çalışma; kedilerde genel anestezi için yaygın olarak kullanılan medotomidin-ketamin anestezisi ile zolazepam -tiletamin anestezisinin hematolojik ve biyokimyasal parametreler üzerinde oluşturduğu etkileri karşılaştırmak ve klinik yönden uygulanabilirliğini araştırmak amacıyla gerçekleştirildi. Çalışmanın materyalini 32 adet kedi oluşturdu. Kedilerin 19 adeti dişi, 13 adeti ise erkek kedi idi. Kediler 6 ay ile 3 yaş arası ve $5.3 \pm 2.4 \mathrm{~kg}$ canlı ağırlığa sahiptiler. Çalışmamız; medetomidin ( $80 \mathrm{mcg} / \mathrm{kg} \mathrm{im})$-ketamin $(10 \mathrm{mg} / \mathrm{kg} \mathrm{im})$ grubu (Grup I) $16 \mathrm{kedi}$, zolazepam-tiletamin $(15 \mathrm{mg} / \mathrm{kg}$ im) grubu (Grup II) 16 kedi olmak üzere 2 gruptan oluştu. Tüm kedilerden 0. dakika, 120. dakika,12. saat ve 24. saatlerde V. cephalica antebrachiden hematolojik ve biyokimyasal ölçümler için kan alındı. Yapılan istatistiksel değerlendirmede; İki grup arasında; hemoglobin (HGB) 120. dakika, lenfosit (LENF) 24. saat, lökosit (WBC) 0. dakika, kan üre azotu (BUN) 12. saat, glikoz (GLU) 120. dakika ölçümlerinde anlamlı fark bulundu $(P<0.05)$. HGB, LENF, WBC, kreatin $(C K)$, alanin aminotransferaz (ALT), aspartat aminotransferaz (AST) ve GLU ölçümlerinin 1. ve 2. gruplarında 0. dakika, 120. dakika, 12. saat ve 24. saatteki ölçümleri arasında, granulosit (GRAN) ve eosinofil (EOS) ölçümlerinin 1. grubunda 0 . dakika, 120. dakika, 12. saat ve 24 . saatteki ölçümleri arasında, gamma glutamil tranpeptidaz (GGT), ölçümlerinin 2. grubunda 0 . dakika, 120. dakika, 12. saat ve 24. saatteki ölçümleri arasında anlamlı fark bulundu $(P<0.05)$. Sonuç olarak; medotomidin-ketamin ve zolazepam-tilatamin anestezisinin kedilerde hematolojik ve biyokimyasal parametreler üzerine etkilerinin olduğu ancak bu etkinin fizyolojik sınırlar içerisinde kaldığı belirlendi. Ancak anestezi bulguları yönünden medotomidin-ketamin anestezisinin zolazepam-tiletamin anestezisine göre daha iyi anestezi sağladığı belirlendi.

Anahtar kelimeler: Kedi, ketamin, medetomidin, tiletamin, zolazepam

\section{Comparison of the Effects of Medetomidine-Ketamine and Zolazepam-Tiletamine Anesthesia on Hematologic} and Biochemical Parameters in Cats

Summary: The aim of this study was to compare the effects of medotomidine-ketamine anesthesia and zolazepamtiletamine anesthesia on hematological and biochemical parameters and to investigate its clinical applicability. The study material consisted of 32 cats. There were 19 female and 13 male cats. The cats were between 6 months and 3 years and had a live weight of $5.3 \pm 2.4 \mathrm{~kg}$. Our study; medetomidine $(80 \mathrm{mcg} / \mathrm{kg} \mathrm{im})$-ketamine $(10 \mathrm{mg} / \mathrm{kg} \mathrm{im}) \mathrm{group}$ (Group I) consisted of 16 cats and zolazepam-tiletamine $(15 \mathrm{mg} / \mathrm{kg} \mathrm{im}$ ) group (Group II) consisted of 16 cats. Of all cats, 0 minutes, 120 minutes, 12. hours and 24 hours. Blood was taken for $v$. cephalica antebrachidene for hematological and biochemical measurements. In statistical evaluation; Between the two groups; There was a significant difference in hemoglobin (HGB) $120^{\text {th }}$ minute and lymphocyte (LENF) $24^{\text {th }}$ hour, leukocyte (WBC) 0 minutes, blood urea nitrogen (BUN) $12^{\text {th }}$ hour, glucose (GLU) $120^{\text {th }}$ minute measurements were significantly different $(P<0.05)$. HGB, LENF, WBC, creatine (CK), alanine aminotransferase (ALT), aspartate aminotransferase (AST) and GLU measurements in the 1 st and 2 nd groups of the $0^{\text {th }}$ minute, $120^{\text {th }}$ minute, $12^{\text {th }}$ hour and $24^{\text {th }}$ hour measurements, granulocyte (GRAN) and eosinophils (EOS) measurements in the first group the $0^{\text {th }}$ minute, $120^{\text {th }}$ minute, $12^{\text {th }}$ hour and $24^{\text {th }}$ hour, in the second group of gamma glutamil tranpeptidase (GGT) measurements, there was a significant difference between the measurements at $0^{\text {th }}, 120^{\text {th }}$ minutes, $12^{\text {th }}$ and $24^{\text {th }}$ hours $(P<0.05)$. As a result; the effects of medotomidine-ketamine and zolazepam-tiletamine anesthesia on hematological and biochemical parameters in cats were determined, but this effect remained within physiological limits. However, in terms of anesthesia findings, medotomidine-ketamine anesthesia was found to provide better anesthesia than zolazepam- tiletamine anesthesia.

Key words: Cat, ketamine, medetomidine, tiletamine, zolazepam

Geliş Tarihi/Submission Date : 28.01.2020

Kabul Tarihi/Accepted Date : 04.05.2020

*Bu makale Erciyes Üniversitesi Bilimsel Araştırma Projeleri Birimi tarafından desteklenen TYL- 2018-8398 kodlu proje ve "Kedilerde Medetomidin-Ketamin ve Zolazepam-Tiletamin Anestezilerinin Hematolojik ve Biyokimyasal Parametreler Üzerine Etkilerinin Karşılaştırııması" başıklı tez çalışmasından üretilmiştir.

\section{Giriş}

Premedikasyon, genel anesteziyi başlatmadan önce değişik yollarla bir veya birkaç ilacın uygulanmasıdır. Preanestezi, hayvanın daha kolay bir şekilde anesteziye girişine, anestezinin devamına olanak sağlar. 
Preanestezik ilaçlar ya tek başına ya da birkaç ilaç ile kombine halde kullanılırlar. Bu ilaçlar; sedasyonu sağlamak, anesteziye girişi kolaylaştırmak, oluşabilecek komplikasyonları engellemek ve kullanılacak genel anestezik ilaç miktarını azaltmak için kullanılır (Apaydın, 2019; Koç ve Sarıtaş, 2004).

Medetomidin, küçük hayvan hekimliğinde yaygın olarak kullanılan $\alpha 2$-adrenoseptör agonisti bir ilaçtır. $\alpha 2-$ adrenoseptör agonistlerin temel amacı sedasyon oluşturmalarıdır. Bu etkilerinin yanı sıra sentral ve spinal etkilerine bağlı olarak kaslarda relaksiyon ve analjezi meydana getirirler (Kanda ve Hikasa, 2008; Ko ve ark., 2007; Yaygıngül ve Belge, 2018). Sedatif etkilerinin süresi ortalama 1-2 saat olmakla beraber verilen doza bağlıdır ve zaman zaman 6 saate kadar uzayabilir. Analjezik etki sedasyon süresinden daha kısadır ve yaklaşık 1 saat kadardır. Güçlü etkilerine rağmen ağrılı cerrahilerde tek başına kullanılmazlar. Medetomidinin en büyük avantajı, etkilerinin atipamezol ile tersine çevrilebilmesidir (Çetinaslan ve Apaydın, 2008). Premedikasyon için kullanılırsa doz miktarının düşürülmesi tercih edilir. Kedilerde kullanılan doz $80-150 \mathrm{mcg} / \mathrm{kg}$ im arasında değişmektedir. Kedilerde Medetomidin ile doza bağlı sedasyon oluşur (Topal, 2005). Kediler de \% 90 oranında kusma, trombositlerde kümeleşme, plazma insülin düzeyini düşürecek hiperglisemiye neden olma gibi yan etkileri bulunmaktadır (Çetinaslan ve Apaydın, 2008; Kanda ve Hikasa, 2008).

Zolazepam; dissosiyatif ilaç grubunda yer alan tiletamin ile kombine olarak kullanılır. Suda çözünürlüğü olan bir benzodiazepin türevidir. Zolazepam'ın farmakokinetik etkisi diazepam ve midazolam'a benzer. Diazepam ve midazolamdan daha az etkilidir, yüksek dozları ise eksitasyon ve ruhsal değişimlere neden olabilir (Hamton ve ark., 2019; Li ve ark., 2015; Mair ve ark., 2014; Yanmaz ve ark., 2017).

Ketamin ve tiletamin ile oluşturulan anestezilerde refleksler büyük oranda değişmeden kalır. Hastalarda sese, ışığa ve diğer uyarılara karşı hassasiyet artmıştır. Kas tonusu artar, hatta rijitite oluşur. Vücut gergin haldedir. Visseral ağrıyı tam olarak ortadan kaldırmadığı için abdominal operasyonlarda tek başına kullanılmamalıdır (Topal, 2000). Dissosiyatif anestezikler hem iv hem de im yolla uygulanabilirler. Bunun nedeni anestezik doz güvenlik sınırının geniş olmasıdır. Solunumda ara sıra soluk tutma şeklinde göze çarpan bir etki oluşturur. Kardiovasküler sistemde diğer anesteziklerden farklı olarak kalp hızı artar, kan basıncı yükselir ve kardiak kontraktilite artar. Karaciğerde metabolize olur ve böbrek yoluyla değişmeden atııılar. Karaciğer ve böbrek rahatsızlığı olan hastalarda dikkatli ve düşük doz uygulanmalıdır (Apaydın, 2019; Topal, 2005).

Ketamin; dissosiyatif bir anestezi olarak bilinçsizlik ve somatik anestezi içeren kataleptik etki oluşturur. Diğer sinir sistemini deprese eden ilaçlara göre avantajı kardiovasküler sistemi stimüle etmesidir (Gebremedhin ve ark., 2018; Karasu ve ark., 2018; Kaya ve ark., 2002). Uygun bir premedikasyon uygulamasını takiben $10-30 \mathrm{mg} / \mathrm{kg}$ im uygulandığında 4560 dakika, $5-10 \mathrm{mg} / \mathrm{kg}$ iv uygulandığında $15-20$ dakika süren bir anestezi sağlar. Anestezi süresini uzatmak için başlangıç dozunun yarısı uygulanabilir. Ketamin kedilerin karaciğerinde az oranda metabolize olur ve enjekte edilen miktarın büyük bir bölümü değişime uğramadan atılır. Ketamin, hepatik ve renal disfonksiyonu olan hayvanlarda dikkatli bir şekilde uygulanmalıdır (Apaydın, 2019; Topal, 2005).

Tiletamin-zolazepam kombinasyonu; kedi ve köpeklerde diagnostik ve küçük cerrahi işlemler için im ve iv olarak kullanılan; düşük dozlarda kullanıldığında sedasyon yüksek dozlarda ise anestezi sağlayan etkili bir ilaç kombinasyonudur (Kaya ve ark., 2002). Tiletamin-zolazepam birçok evcil ve vahşi hayvan türünde de kullanılmaktadır (Hampton ve ark., 2019). Tiletamin, kataleptik özellikte, beyaz renkli, suda kolay çözülen immobilizasyon ve analjezik etkisi ketamine oranla daha uzun süreli dissosiyatif anestezik madde grubundadır. Genellikle zolazepam ile birlikte kullanıIır. Tiletamin, kasları gevşetmez veya kranial sinir ve spinal refleksleri etkilemez. Bununla birlikte, zolazepam ilavesi ile kas gevşemesi oluşur (Ko ve ark., 2007). Kedilerde tiletamin-zolazepam im ve iv enjeksiyonundan 1.5 - 6 dakika sonra cerrahi anestezi başlar. Kedilerde bu kombinasyonun güvenlik sınırı geniş olup, önerilen dozların 4.5 katına kadar olumsuz etki görülmez. Kedi ve köpeklerde $10 \mathrm{mg} / \mathrm{kg}$ iv, $15-25 \mathrm{mg} / \mathrm{kg}$ im uygulanabilir (Topal, 2005). Güvenlik sınırının genişliği, anesteziye girişin hızlı ve rahat olması, kas gevşemesinin ve ağrı kesici etkisinin iyi olması, kalp ve solunum sistemlerine baskılayıcı etkisinin hızlı ve rahat şekillenmesi ilacın olumlu yönleridir. Tiletamin-zolazepam tek başına veya diğer ilaçlarla kombine olarak da kullanılabilmektedir (Ko ve ark., 2007; Lu ve ark., 2014; Spada ve ark., 2015).

Anestezi öncesi, sırasında ve sonrasında hastadan alınan kan örneklerinden biyokimyasal, hematolojik ölçümler başarılı bir anestezinin temelini oluşturur. Hayvanın anestezi öncesi durumunu belirlemek ve uygun anestezik ilacın seçimi için kan parametrelerinin belirlenmesi önemli ve gereklidir. Dolayısıyla bu parametreleri etkilemeyen ya da en az etkileyen anestezik ilaçlar kullanılmalıdır (Çetinaslan ve Apaydın, 2008; Rashid, 2017; Zlateva ve Marinov, 2015).

Çalışmamı; medetomidin-ketamin ve zolazepamtiletamin anestezisinin hematolojik ve biyokimyasal parametreler üzerine etkilerinin karşılaştırılarak uygun olan anestezi seçeneğinin belirlenmesi ve klinik yönden uygulanabilirliğinin araştırılması amacıyla gerçekleştirildi. 


\section{Gereç ve Yöntem}

Çalışmanın materyalini; 19 adet dişi, 13 adet erkek kedi olmak üzere toplam 32 adet kedi oluşturdu. Kediler 6 ay ile 3 yaş arası ve $5.3 \pm 2.4 \mathrm{~kg}$ canlı ağırlığa sahiptiler.

Çalışma öncesinde Erciyes Üniversitesi Hayvan Deneyleri Yerel Etik Kurulu'un dan (10.01.2018 tarih ve 18/012 sayılı karar) izin alındı. Çalışma materyallerini Erciyes Üniversitesi Veteriner Fakültesi Eğitim Araştırma ve Uygulama Hastanesi Cerrahi Kliniği ile Ankara İncek Petlife Veteriner Kliniği'ne radyolojik tanı, minör cerrahi, orchioktemi, ovariohisterektomi ve kırık operasyon için getirilen 32 adet kedi oluşturdu.

Anestezi öncesi 12 saat tüm kediler aç bırakıldı, sadece su verildi. Bütün olguların klinik muayeneleri yapıldı. V. cephalica antebrachi ye kateter yerleştirildi.

Çalışmamız; medetomidin-ketamin grubu (Grup I) 16 kedi, zolazepam-tiletamin grubu (Grup II) 16 kedi olmak üzere 2 gruptan oluştu. Tüm kedilerden 0 . dak., 120. dak.,12. saat ve 24. saatlerde v. cephalica antebrachiden hematolojik ve biyokimyasal ölçümler için $5 \mathrm{ml}$ kan alındı. Bu kanlar; 1 adet EDTA' ı, 1 adet vakumlı serum tüpüne paylaştırıldı. EDTA'lı tüplere alınan kan örnekleri pıhtılaşma problemiyle karşılaşılmaması ve tüm kanın EDTA ile homojen bir şekilde karışması için düzgün dairesel hareketlerle sallandı.

Grup I deki 16 kedi için preanestezik olarak $80 \mathrm{mcg} /$ $\mathrm{kg}$ im medetomidin (Tomidin $®$, Provet), 10-15 dakika sonra genel anestezik olarak $10 \mathrm{mg} / \mathrm{kg}$ im ketamin (Ketasol \%10) ®, Richterpharma ag) uygulandı. Grup II de ki 16 kedi için zolazepam- tiletamin (Zolatil囚 50, Virbac) ugulandı. 1 şişe içeriği, 5 ml' lik enjeksiyonluk su ile sulandırılarak $1 \mathrm{ml}$ ' si $50 \mathrm{mg}$ ' lık etken madde (25 mg tiletamin + $25 \mathrm{mg}$ zolazepam) içeren Zolatil ${ }^{\circledR}$ 50 'den $15 \mathrm{mg} / \mathrm{kg}$ im uygulandı. Olguların operasyon süreleri ortalama 45-60 dakika sürdü. Kedilerin postanestezi dönemi yoğun bakım özelliği olan kafeslerde gerçekleştirildi. Bütün refleksler yerine geldikten sonra olgular normal bakım ünitelerine alındı.

İki grup için de EDTA' I tüplere aldığımız kan örneklerinden hematolojik inceleme için; eritrosit (RBC), hematokrit (HCT), hemoglobin (HGB), lenfosit (LENF), lökosit (WBC), granulosit (GRAN), eosinofil (EOS), trombosit (PLT) değerlerine bakıldı. Bu ölçümler için Mindray BC-2800 Vet China marka otomatik kan sayım cihazından yararlanıldı.

İki grup için de vakumlu serum tüplerine aldığımız kan örneklerinden biyokimyasal inceleme için; kreatin (CK), kan üre azotu (BUN, gamma glutamil tranpeptidaz (GGT), alanin aminotransferaz (ALT), aspartat aminotransferaz (AST) ve glikoz (GLU) değerlerine bakıldı. Bu ölçümler için RANDOX rx monaco UK tam otomatik biyokimya cihazı kullanıldı.
İstatistik analizler: Verilerin normal dağılıma uygunluğu $Q-Q$ plot, histogram grafikleri ve Shapiro Wilk testi ile değerlendirildi. Sıfırıncı dak, 120. dak., 12. saat ve 24. saatler arasındaki farklılıkların istatistiksel olarak önem kontrolleri Friedman testi, farklıığın önemli olduğu parametrelerde Bonferroni düzeltmeli Wilcoxon testi ile yapıldı. Gruplar arasındaki farklılıkların istatistiksel olarak önem kontrolleri ise Mann Whitney $U$ testi ile yapıldı. Verilerin tanımlayıcı istatistikleri Ortalama \pm Standart hata ile gösterildi. İstatistiksel analizlerde NCSS 9 programı kullanıldı.

\section{Bulgular}

Grup I deki olgularımıza medetomidin-ketamin uygulandı. Yedinci olguda solunum sayısı 32/dak dan 12/ dak.ya düştüğü için doxapram $5 \mathrm{mg} / \mathrm{kg}$ iv (Doxaprol Provet) uygulandı. Onbirinci olguda uyanma aynı grubun diğer olgularına göre 12 dakika daha erken oldu. Ondördüncü olguda uyanma 21 dakika daha geç şekillendi. Hipotermi şekillenen 15. olgunun vücut sıcaklığı $\left(34.8^{\circ} \mathrm{C}\right)$ sıcak su torbalarıyla normale döndürüldü. Grup I olgularında uyanma süresi Grup II ye göre 10-20 dakika aralığında daha geç gerçekleşirken, uyanmadaki konfor Grup II ye göre daha iyi idi.

Grup II de ki tüm olgular da anestezi süresince solunumun çok yüzeysel olduğu, palpebral reflekslerin çok belirgin olduğu belirlendi. Kediler için uzun süren operasyonlarda önerilen dozun ( $15 \mathrm{mg} / \mathrm{kg}$ ) yeterli olmadığı görüldü. Zolazepam-tiletamin grubunda uyanma sürelerinin medetomidin-ketamin grubuna oranla 10-20 dakika daha erken şekillendiği görüldü. Zolazepam-tiletamin grubunda olguların 2 si hariç (25 $\mathrm{mg} / \mathrm{kg}$ im uygulanan 15 ve 16 no lu olgular) diğerlerinin hepsinde anestezi çıkışında eksitasyon gözlendi.

İki grup arasında; HGB değişkeninin 120. dakika ölçümleri $(P=0.035)$, LENF değişkeninin 24. saatteki ölçümleri $(P=0.047)$, WBC değişkeninin 0 . dakikadaki ölçümleri $(P=0.039)$, BUN değişkeninin 12. saatteki ölçümleri $(P=0.043)$, GLU değişkeninin 120. dakika ölçümleri $(P=0.007)$ arasında anlamlı fark bulundu $(P<0.05)$. Diğer değişkenler bakımından gruplar arasında anlamlı farklılık bulunmadı $(P>0.05)$.

HGB, LENF, WBC, creatin, ALT, AST VE GLU değişkenlerinin 1. ve 2. gruplarında 0. dakika, 120. dakika, 12. saat ve 24. saatteki ölçümleri arasında anlamlı fark bulundu $(P<0.05)$. GRAN ve EOS değişkeninin 1. grubunda 0 . dakika, 120 . dakika, 12 . saat ve 24 . saatteki ölçümleri arasında anlamlı fark bulundu $(P<0.05)$. GGT değişkeninin 2. grubunda 0. dakika, 120. dakika, 12 . saat ve 24 . saatteki ölçümleri arasında anlamlı fark bulundu $(P<0.05)$. Diğer değişkenlerin grupları içinde tekrar eden ölçümler arasında anlamlı farklılık bulunmadı $(P>0.05)$ (Tablo 1). 
Tablo 1. Kedilerde medetomidin-ketamin ve zolazepam-tiletamin anestezilerinin hematolojik ve biyokimyasal parametrelerinde, grupların ve tekrarlayan ölçüm sonuçlarının istatistiksel karşılaştırılması.

\begin{tabular}{|c|c|c|c|c|c|}
\hline \multirow{2}{*}{ Değişkenler } & \multicolumn{4}{|c|}{ Zaman (Ort \pm St Hata) } & \multirow{2}{*}{$\begin{array}{c}\text { P Değeri } \\
\text { (Friedman Tes- } \\
\text { ti) }\end{array}$} \\
\hline & 0.Dakika & 120. Dakika & 12. Saat & 24. Saat & \\
\hline \multicolumn{6}{|l|}{ RBC } \\
\hline $\begin{array}{l}\text { 1.Grup } \\
\text { 2.Grup }\end{array}$ & $\begin{array}{c}10.20 \pm 0.63 \\
9.80 \pm 0.78\end{array}$ & $\begin{array}{l}7.72 \pm 0.60 \\
9.07 \pm 0.57\end{array}$ & $\begin{array}{l}8.60 \pm 0.52 \\
8.91 \pm 0.70\end{array}$ & $\begin{array}{l}9.06 \pm 0.60 \\
7.97 \pm 0.62\end{array}$ & $\begin{array}{l}0.133 \\
0.157\end{array}$ \\
\hline $\begin{array}{c}\text { P Değeri } \\
\text { (Mann Whitney U } \\
\text { Testi) }\end{array}$ & 0.780 & 0.094 & 1.000 & 0.196 & \\
\hline \multicolumn{6}{|l|}{$\mathrm{HCT}$} \\
\hline $\begin{array}{l}\text { 1.Grup } \\
\text { 2.Grup }\end{array}$ & $\begin{array}{l}44.83 \pm 2.95 \\
43.31 \pm 2.93\end{array}$ & $\begin{array}{l}32.67 \pm 2.46 \\
41.16 \pm 3.85\end{array}$ & $\begin{array}{c}36.91 \pm 2.09 \\
40.1 \pm 3.94\end{array}$ & $\begin{array}{l}39.39 \pm 2.61 \\
34.56 \pm 2.31\end{array}$ & $\begin{array}{l}0.073 \\
0.069\end{array}$ \\
\hline $\begin{array}{c}\text { P Değeri } \\
\text { (Mann Whitney U } \\
\text { Testi) } \\
\end{array}$ & 0.724 & 0.061 & 1.000 & 0.110 & \\
\hline \multicolumn{6}{|l|}{ HGB } \\
\hline $\begin{array}{l}\text { 1.Grup } \\
\text { 2.Grup }\end{array}$ & $\begin{array}{l}15.44 \pm 0.66^{\mathrm{a}} \\
16.56 \pm 1.21^{\mathrm{a}}\end{array}$ & $\begin{array}{c}11.41 \pm 0.84^{\mathrm{b}} \\
14.39 \pm 1.12^{\mathrm{ab}}\end{array}$ & $\begin{array}{l}12.99 \pm 0.79^{\mathrm{ab}} \\
14.69 \pm 1.45^{\mathrm{ab}}\end{array}$ & $\begin{array}{c}14.35 \pm 0.98^{\text {ab }} \\
12.68 \pm 0.83^{b}\end{array}$ & $\begin{array}{l}0.010 \\
0.033\end{array}$ \\
\hline $\begin{array}{c}\text { P Değeri } \\
\text { (Mann Whitney U } \\
\text { Testi) } \\
\end{array}$ & 0.752 & 0.035 & 0.780 & 0.119 & \\
\hline \multicolumn{6}{|l|}{ LENF } \\
\hline $\begin{array}{l}\text { 1.Grup } \\
\text { 2.Grup }\end{array}$ & $\begin{array}{l}10.14 \pm 3.86^{a} \\
11.73 \pm 3.09^{a} \\
\end{array}$ & $\begin{array}{l}4.22 \pm 1.27^{\mathrm{b}} \\
4.13 \pm 0.87^{\mathrm{b}}\end{array}$ & $\begin{array}{c}9.68 \pm 4.72^{b} \\
11.54 \pm 5.41^{b} \\
\end{array}$ & $\begin{array}{l}5.06 \pm 1.66^{\mathrm{b}} \\
8.20 \pm 2.03^{\mathrm{ab}}\end{array}$ & $\begin{array}{l}0.002 \\
0.011\end{array}$ \\
\hline $\begin{array}{c}\text { P Değeri } \\
\text { (Mann Whitney U } \\
\text { Testi) } \\
\end{array}$ & 0.102 & 0.491 & 0.224 & 0.047 & \\
\hline \multicolumn{6}{|l|}{ WBC } \\
\hline $\begin{array}{l}\text { 1.Grup } \\
\text { 2.Grup }\end{array}$ & $\begin{array}{l}13.93 \pm 2.63^{\mathrm{ab}} \\
21.32 \pm 3.52^{\mathrm{ab}}\end{array}$ & $\begin{array}{c}9.97 \pm 1.94^{\mathrm{a}} \\
12.43 \pm 1.69^{\mathrm{a}}\end{array}$ & $\begin{array}{l}19.45 \pm 5.22^{b} \\
25.03 \pm 5.42^{b}\end{array}$ & $\begin{array}{c}16.53 \pm 3.46^{\mathrm{b}} \\
20.51 \pm 2.82^{\mathrm{ab}}\end{array}$ & $\begin{array}{l}0.001 \\
0.003\end{array}$ \\
\hline $\begin{array}{c}\text { P Değeri } \\
\text { (Mann Whitney U } \\
\text { Testi) }\end{array}$ & 0.039 & 0.110 & 0.196 & 0.128 & \\
\hline \multicolumn{6}{|l|}{ GRAN } \\
\hline $\begin{array}{l}\text { 1.Grup } \\
\text { 2.Grup }\end{array}$ & $\begin{array}{c}6.28 \pm 1.09^{\mathrm{ab}} \\
8.50 \pm 1.19\end{array}$ & $\begin{array}{l}5.36 \pm 1.20^{\mathrm{a}} \\
7.76 \pm 1.09\end{array}$ & $\begin{array}{c}11.16 \pm 1.78^{b} \\
12.71 \pm 1.94\end{array}$ & $\begin{array}{c}10.74 \pm 1.73^{b} \\
11.59 \pm 1.87\end{array}$ & $\begin{array}{l}<0.001 \\
0.085\end{array}$ \\
\hline $\begin{array}{c}\text { P Değeri } \\
\text { (Mann Whitney U } \\
\text { Testi) }\end{array}$ & 0.160 & 0.067 & 0.539 & 0.752 & \\
\hline
\end{tabular}

${ }^{*} a, b, c$ : Aynı satırda farklı harf taşıyan gruplar istatistiksel olarak farklıdır.

RBC (eritrosit), HCT (hematokrit), HGB (hemoglobin), LENF (lenfosit), WBC (lökosit), GRAN (granulosit), EOS (eosinofil), PLT (trombosit), CK (kreatin), BUN (kan üre azotu ), GGT (gamma glutamil tranpeptidaz), ALT (alanin aminotransferaz), AST (aspartat aminotransferaz), GLU (glikoz)

\section{Tartışma ve Sonuç}

Medetomidin, son yıllarda yaygın olarak kullanılan bir a2-adrenoseptör agonisti bir ilaçtır. Kaslarda relaksiyon ve analjezi meydana getirir. Sedatif etkilerinin süresi ortalama 1-2 saat olmakla beraber verilen doza bağlıdır ve zaman zaman 6 saate kadar uzayabilir. Analjezik etki sedasyon süresinden daha kısadır ve yaklaşık 1 saat kadardır. Güçlü etkilerine rağmen ağrılı operasyonlarda tek başına kullanılmazlar. Kediler de \% 90 oranında kusma, trombositlerde kümeleşme, plazma insülin düzeyini düşürecek hiperglisemiye neden olma gibi yan etkileri bulunmaktadır (Apaydın, 2019; Çetinaslan ve Apaydın, 2008; Yaygıngül ve Belge, 2018; Kanda ve Hikasa, 2008). Ça-
Iışmamızın Grup 1 deki olgularında premedikan ilaç olarak medetomidin kullanıldı. Bütün olgularımızda sedasyon sağlanırken operasyon süresince de analjezinin sağlandığı görüldü. Ketamin ile birlikte uygulandığından dolayı ideal bir anestezi sağlandı. Ağrıı operasyonlarda tek başına medetomidin kullanılmasının uygun olmayacağına karar verildi. Medetomidin uygulanan bütün olgularımızda kusma görüldü. GLU değişkeninin 120. dakikadaki ölçümü bakımından anlamlı fark bulundu $(P=0.007)$. 0 . dakika ölçüm değeri $100.90 \pm 8.64$ iken medetomin uygulandıktan sonra 120. dakika ölçüm değerleri 193.67£19.96, 12. saat $116.42 \pm 10.61$ ve 24 . saat ölçüm değeri ise $101.06 \pm 4.51$ olarak kaydedildi. Medetomidin uygulan- 
dıktan sonra kan glikoz düzeyinin arttığı ancak bunun hiperglisemi oluşturacak düzeye kadar çıkmadığı, etkisinin geçmesinden sonra kan glikoz düzeyinin tekrar düştüğü görüldü.

Zolazepam, tiletamin ile kombine olarak kullanılır. Suda çözünürlüğü olan bir benzodiazepin türevidir. Yüksek dozları ise eksitasyon ve ruhsal değişimlere neden olabilir (Hamton ve ark., 2019; Mair ve ark., 2014). Kedi ve köpeklerde diagnostik ve küçük cerrahi işlemler için im ve iv olarak kullanılan; düşük dozlarda kullanıldığında sedasyon yüksek dozlarda ise anestezi sağlayan etkili bir ilaç kombinasyondur (Kaya ve ark., 2002). Kedilerde bu kombinasyonun güvenlik sınırı geniş olup, önerilen dozların 4.5 katına kadar olumsuz etki görülmez. Kedi ve köpeklerde 10 $\mathrm{mg} / \mathrm{kg}$ iv, $15-25 \mathrm{mg} / \mathrm{kg}$ im uygulanabilir (Topal, 2005). Güvenlik sınırının genişliği, anesteziye girişin hızlı ve rahat olması, kas gevşemesinin ve ağrı kesici etkisinin iyi olması, kalp ve solunum sistemlerine baskılayı$\mathrm{Cı}$ etkisinin hızlı ve rahat şekillenmesi ilacın olumlu yönleridir. Salivasyonu artırması ve hazırlanan çözeltinin 3 gün içerisinde tüketiminin zorunlu olması ilacın olumsuz yönleridir. Uygulandıktan sonra hipotermi, taşikardi, kusma ve ajitasyon gibi olumsuz etkiler görülebilir (Ko ve ark., 2007; Lu ve ark., 2014; Spada ve ark., 2015; Li ve ark., 2015; Yanmaz ve ark., 2017). Araştırmamızda 5 ml' lik enjeksiyonluk su ile sulandırılarak $1 \mathrm{ml}$ ' si $50 \mathrm{mg}$ ' lık etken madde $(25 \mathrm{mg}$ tiletamin $+25 \mathrm{mg}$ zolazepam) içeren Zolatil $(50$ 'den $15 \mathrm{mg} / \mathrm{kg}$ im uygulandı. Olgularımızın cerrahi süresi ortalama 60 dakika idi. Anesteziye giriş hızlı ve rahat oldu. Ancak bazı olgularda salivasyon artışı gözlendi. Uygulanan $15 \mathrm{mg} / \mathrm{kg}$ im dozun yeterli olmadığı belirlendi. Cerrahi sırasında olguların ağrı duyduğu ve bazı olgularda idame doz uygulaması yapılması gerektiği görüldü.

Ketamin kas gevşemesini sağlamak, nöbet veya konvülsiyonları önlemek için $\alpha 2$ agonisti ile birlikte kullanılabilir (Topal, 2005). Tek başına Ketamin ile anestezide genellikle aşırı tükrük salgısı, kas sertliği ve çırpınma oluşur (Çetinaslan ve Apaydın, 2008). Medetomidine-ketamine kombinasyonu, hızı indüksiyon, iyi kas gevşemesi, iyi analjezi ve bradikardi ile karakterize kediler için uygun bir anestezi oluşturur (Heidari ve ark., 2017). Çalışmamızda ketamin tek başına kullanılmadı. Preanestezik olarak $80 \mathrm{mcg} / \mathrm{kg}$ im medetomidin, 10-15 dakika sonra genel anestezik olarak 10 $\mathrm{mg} / \mathrm{kg}$ im ketamin uygulandı. Medetomidine-ketamine anestezi protokolünün, hızlı indiksüyon, iyi kas gevşemesi, iyi analjezi sağlayan kediler için uygun bir anestezi oluşturduğu belirlendi.

Hayvanın anestezi öncesi kan parametrelerinin belirlenmesi, güvenli anestezi protokolünün uygulanması yönü ile önemlidir. Anestezi öncesi böbrek ve karaciğer fonksiyon testleri hastanın prognozu yönünden önemlidir. Karaciğer ve böbrek fonksiyon değerlerinin fizyolojik sınırlar içerisinde olmaması patolojik bir durumun göstergesidir. Ancak bu değerler tek başına tanı konulması için yeterli değildir (Apaydın ve Koç, 2005; Çetinaslan ve Apaydın, 2008; Rashid, 2017; Zlateva ve Marinov, 2015). Araştırmamı iki anestezi protokolünün hematolojik ve biyokimyasal parametrelere olan etkilerini içermektedir. Çalışmamız; anestezi öncesi hastaların hematolojik ve biyokimyasal kan değerlerinin belirlenmesinin, gerek yapılan cerrahiyi gerekse uygulanan anestezi protokolünü direk etkilediğini ortaya koydu. Bu nedenle preanestezi döneminde hastadan alınan kan örneklerinden elde edilecek bu laboratuvar bulgularının değerlendirip buna göre anestezi protokolü belirlenmesinin temel prensip olması gerektiği görüldü.

Tavşanlarda xylazine-zolazepam-tiletamin ve xylazine-ketamine genel anestezilerinin karşılaştırıldığı çalışmada (Kaya ve ark., 2002); anestezi süresi, derinliği ve fizyolojik parametreler yönünden xylazinezolazepam-tiletamin anestezisinin tercih edilebilir bir anestezi yöntemi olduğu belirlenmiştir. Araştırmamız medetomidin-ketamin ile zolazepam-tiletamin anestezi protokollerinin hematolojik ve biyokimyasal parametreler üzerine etkilerinin karşılaştırılmasını kapsamaktadır. Bu parametreler üzerine her iki anestezi protokolünün etkisi fizyolojik sınırlar içerinde oldu. Ancak kedilerde medetomidin-ketamin anestezisinin zolazepam-tiletamin anestezisine göre daha iyi sonuçlar verdiği gözlendi. Zolazepam-tiletamin grubunda Kaya ve ark. (2002) ikinci bir premedikan ilaç olan xylazin kullanmışlardır. Biz çalışmamızda sadece zolazepam ve tiletamin içeren ilaç kullandık, bu nedenle tavşanlarda önerilebilen bir protokol olmasına rağmen kediler için sadece zolazepam-tiletamin anestezisininde $15 \mathrm{mg} / \mathrm{kg}$ dozun uygun olamayacağı ya da Kaya ve ark. (2002) tarafından uygulandı gibi ilave bir premedikan ilacın kullanılması gerektiği sonucuna varıldı.

Tiletamin-zolazepam-xylazin ve ketamin-xylazin kombinasyonunun buzağılarda oluşturduğu anestezik etkinin ortaya konmasını amaçlayan çalışmada (Şındak ve ark., 2003); tiletamin-zolazepam-xylazin kombinasyonunun, ketamin-xylazin kombinasyonundan daha etkili ve uzun süreli anestezi oluşturduğu belirlenmiştir. Araştırmamızda zolazepam-tiletamin uygulandı. İkinci bir premedikan ilaç uygulanmadı. Bu nedenle ideal anestezi sonuçları elde edilemedi. Ancak zolazepam-tilemanın protokolünün değişik dozları araştırma konusu olabileceği düşünüldü. Çalışmamızda $15 \mathrm{mg} / \mathrm{kg}$ dozun kedi ovariohisterektomi operasyonu için yeterli olmadığı belirlendi.

Kedilerde tiletamin-zolazepam (15 mg/kg im) ve xylazin-ketamin $(2 \mathrm{mg} / \mathrm{kg}-10 \mathrm{mg} / \mathrm{kg})$ anestezisinin karşılaştırıldığı araştırmada (Topal, 2000); preanestezik durum, indüksiyon zamanı, indüksiyon kalitesi, analjezi, kas gevşemesi, sternal pozisyon ve uyanma kalitesi yönünden değerlendirme yapılmıştır. Her iki anestezi protokolünün de uygulanması güvenli bulun- 
muş, ancak xylazin-ketamin uygulamasının tiletaminzolazepama göre daha uzun indüksiyon zamanı ve daha az analjezi oluşturduğu, $15 \mathrm{mg} / \mathrm{kg}$ zolazepamtiletamin dozunun kediler için güvenli bir anestezi oluşturduğu belirlenmiştir. Araştırmamız da zolazepam-tiletamin $15 \mathrm{mg} / \mathrm{kg}$ uygulandı. Sonuçlarımız; 15 $\mathrm{mg} / \mathrm{kg}$ dozun kediler için yeterli olmadığını gösterdi.

Köpeklerde medetomidinin 15 mg/kg dozunun klinik ve hematolojik parametrelere olan etkilerini belirleyen araştırmada (Akbar ve ark., 2014); medetomidinin güvenli bir anestezi ve hiçbir komplikasyon oluşmadığı belirlenmiştir. Çalışmamızda medetomidin $40 \mathrm{mcg} /$ kg uygulandı ve güvenli bir anestezi sağlandı medetomidin-ketamin grubunda hiçbir komplikasyon ile karşılaşılmadı. Medetomidinin uygun bir premedikan ilaç olduğu görüşüne varıldı.

Tiletamin ve zolazepam anestezik kombinasyonunun klinik ve hematolojik değişkenleri üzerindeki etkisinin araştırıldığı çalışmada (Spada ve ark., 2015); düşük doz (10 mg/kg) tiletamin-zolazepam anestezisi kullanılarak sağlıklı kedilerden maksimum $60 \mathrm{ml}$ kan alınmasının donörler tarafından iyi tolere edildiği görülmüştür. Araştırmamızda zolazepam-tiletamin anestezi protokolü 45-60 dakika sürecek operasyonlar için uygulandı. Çok kısa süreli işlemler için zolazepamtiletamin anestezisi uygulanabileceği ancak uzun süreli cerrahi prosedürler de bu anestezi protokolünün uygun olamayacağı belirlendi. Zolazepamtiletamin grubunun 10 no lu olgusunda sadece radyografik çekim yapıldı. Bu olguda $15 \mathrm{mg} / \mathrm{kg}$ dozun yeterli olduğu görüldü. Ancak cerrahi prosedürler de bu dozun yeterli olmadığı belirlendi.

Tiletamin-zolazepam-xylazin-tramadol kombinasyonunun kedilerde biyokimyasal ve hematolojik parametrelere olan etkisinin (Li ve ark., 2012); fizyolojik sınırlar içerisinde kabul edilebilir olarak değerlendirilmiş ve uygun bir anestezi protokolü olduğu belirlenmiştir. Araştırmamızdaki zolazepam-tiletamin grubun da da hematolojik ve biyokimyasal parametreler istatistiksel farklılıklara rağmen fizyolojik sınırlar içerinde değişiklikler gösterdi. Zolazepam tiletaminin hematolojik ve biyokimyasal parametreleri etkilemediği belirlendi.

Beagle köpeklerinde medetomidinin nörohormonal ve metabolik etkilerini, xylazin ile karşılaştıran araştırıcılar (Ambrisko ve Hikasa, 2002); her iki premedikan ilacın da glukoz düzeyini arttırdığını belirlemişlerdir. Medetomidinin, glukoz metabolizması üzerindeki etkisinin, yalnızca alfa 2-adrenoseptör aracılı etkilere bağlı olmayabileceğini belirlemişlerdir. Çalışmamızın medetomidin-ketamin grubunda glikoz ölçümlerinde 0 . dakika ölçüm değeri 100.90 \pm 8.64 iken medetomin uygulandıktan sonra 120. dakika ölçüm değerleri 193.67 \pm 19.96 olarak belirlendi. Medetomidinin hiperglisemi etkisi olduğu görüldü. Medetomidinin etkisi geçtikten sonra glikoz seviyesi tekrar düştü. Medeto- midinin glikoz metabolizması üzerine etkili olduğu belirlendi.

Tiletamin-zolazepam ve tiletamin-zolazepam-xylazin kombinasyonlarının anestezik etkilerini köpekler üzerinde değerlendiren araştırmacı (Şındak, 1998); ölçüm sonuçlarının hematolojik ve biyokimyasal kan parametrelerinde minimal etkiler meydana getirdiğini, ayrıca mükemmel kas gevşemesi sağlayarak uygun anestezik koşullar oluşturduğunu tespit etmişlerdir. Köpeklerde tiletamin-zolazepam ve tiletaminzolazepam-xylazin kombinasyonlarının pratikte uygulanabileceği, tiletamin-zolazepam-xylazinin, tiletaminzolazepamdan daha etkili ve daha uzun süreli anestezi sağladığı sonucuna ulaşmışlardır. Çalışmamızda zolazepam-tiletamin kedilerde uygulandı. İkinci bir premedikan ilaç uygulanmadı. Ancak protokolümüze xylazin de eklenseydi daha konforlu bir genel anestezi sağlanabileceği belirlendi.

Köpeklerde medetomidin propofol isofluran anestezisinin hematolojik ve biyokimyasal parametreler üzerine etkisini belirleyen çalışmada (Oskay ve Atalan, 2010); propofol uygulandığında apne oluşturması nedeniyle gerekli önlemlerin alınması gerektiği ve bu anestezi protokolünün güvenli bir şekilde kullanılabileceğini bildirmişlerdir. Çalışmamızda; Medetomidin uygulanan grubun hematolojik ve biyokimyasal parametleri fizyolojik sınırlar içerinde etkilediği görüldü. Medetomidinin bu ölçüm değerleri üzerine minumum düzeyde etkisi olduğu belirlendi.

Sonuç olarak; kedilerde medetomidin-ketamin ve zolazepam-tiletamin anestezilerinin hematolojik ve biyokimyasal parametrelere minumum düzeyde etkilediği belirlendi. Bu etkilerin referans aralıklar içerisinde olduğu saptandı. Medetomidin-ketamin anestezisinin zolazepam-tiletamin anestezisine göre daha etkili bir anestezi oluşturduğu belirlendi.

\section{Teşekkür}

$\mathrm{Bu}$ tez çalışmasının yapılmasındaki katkılarından dolayı Erciyes Üniversitesi Bilimsel Araştırma Projeleri Birimi'ne teşekkür ederiz.

\section{Kaynaklar}

Akbar H, Khan MA, Khan MS, Aslam S, Nasir A, Anjum AA. Effects of different doses of medetomidine on clinical and hematological parameters in dogs. J Anim Plant Sci 2014; 24 (3): 730-7.

Ambrisko TD, Hikasa Y. Neurohormonal and metabolic effects of medetomidine compared with xylazine in beagle dogs. Can J Vet Res 2002; 66: 42-9.

Apaydın N, Koç B. Köpeklerde isoflurane ve sevoflurane anestezisinin hemodinamik ve biyokimyasal parametrelere olan etkilerinin karşılaştırılması. Vet Cer Derg 2005;11(1-2-3-4):31-5. 
Apaydın N. Veteriner Anestezi. İkinci Baskı. Malatya: Medipress, 2019; s. 17-44.

Çetinaslan M, Apaydın N. Köpeklerde medetomidinketamin-atipamezol anestezisinin hematolojik ve biyokimyasal parametrelere olan etkileri. Sağlık Bilim Derg 2008; 17(2): 110-6.

Gebremedhin Y, Negash G, Fantay H. Clinical evaluation of anesthetic combinations of xylazineketamine, diazepam-ketamine and acepromazineketamine in dogs of local breed in mekelle, ethiopia. SOJ Vet Sci 2018; 4(2): 1-9.

Hamton CE, Riebold T W, Ronald E. Recovery characteristics of dogs following anesthesia induced with tiletamine-zolazepam, alfaxalone, ketaminediazepam, or propofol and maintained with isoflurane. J Am Vet Med Assoc 2019; 254(12): 1421-6.

Heidari F, Javdani M, Sadegh AB, Nikouseft Z. Does ketamine-midazolam combination act as a routine and safe chemical restraint in cats? Clinical and hemato-biochemical evaluation. Comp Clin Path 2017; 26(4): 793-7.

Kanda T, Hikasa Y. Neurohormonal and metabolic effects of medetomidine compared with xylazine in healthy cats. Can J Vet Res 2008; 72: 278-86.

Karasu A, Altuğ N, Aslan L, Bakır B, Yüksek N. Evaluation of the anesthetic effects of xylazineketamine, xylazine-tiletamine-zolazepam and tiletamine-zolazepam using clinical and laboratory parameters in rabbits. Med Weter 2018; 74 (10): 64652.

Kaya Ü, Apaydın N, Kaya A, Koç B. Tavşanlarda xylazine-tiletamine-zolazepam ve xylazineketamine anestezilerinin kardiovasküler ve respiratorik etkilerinin karşılaştırılması. Vet Cer Derg 2002; 8(3-4): 63-8.

Ko JCH, Abbo LA, Weil AB, Johnson BM, Payton MA. Comparison of anesthetic and cardiorespiratory effects of tiletamine-zolazepam-butorphanol and tiletamine-zolazepam-butorphanolmedetomidine in cats. Vet Ther 2007; 8(3): 164-75.

Koç B, Sarıtaş ZK. Veteriner Anesteziyoloji ve Reanimasyon. Birinci Baskı. Malatya: Medipress, 2004; s. $79-87$.

Li L, Dong J, Lu D, Jiang S, Lin D, Fan H. Effects of tiletamine-zolazepam-xylazine-tramadol combination on biochemical and haematological parameters in cats. Vet Ther 2012; 56: 369-72.

Li L, Dong J, He J, Cui J, Yu X, Tan D, Fan H. Anaesthetic effects of tiletamine-zolazepam-xylazinetramadol combination in cats undergoing surgical sterilization. Acta Vet Brno 2015; 84: 181-5.
Lu DZ, Jiang S, Yu SM, Fan HG. A comparison of anesthetic and cardiorespiratory effects of tiletamine-zolazepam/xylazine and tiletamine-zolazepam/ xylazine/tramadol in dogs. Pak Vet J 2014; 34 (1): 63-7.

Mair A, Kloeppel H, Ticehurst K. A comparison of low dose tiletamine-zolazepam or acepromazine combined with methadone for pre-anaesthetic medication in cats. Vet Anaesth Analg 2014; 41: 630-5.

Oskay B, Atalan G. Köpeklerde medetomidinpropofol-isofluran anestezisinin hematolojik ve biyokimyasal parametrelere olan etkileri. Sağlık Bilim Derg 2010; 19(3);167-74.

Rashid HB. Evaluation of effects of different combinations of selected sedatives on the hematological profile of standing sedates horses. J Anim Plant Sci 2017; 27(6): 1879-87.

Spada E, Proverbio D, Giorgi GBD, Perego R, Valena E, Pepa AD, Baggiani L. Clinical and haematological responses of feline blood donors anaesthetised with a tiletamine and zolazepam combination. J Feline Med Surg 2015; 17(4): 338-41.

Şındak N. Köpeklerde tiletamin-zolazepam ve tiletamin-zolazepam-xylazin anestezisi, Doktara Tezi, Yüzüncü Yıl Üniv Sağ Bil Ens, Van 1998.

Şındak N, Yürekli UF, Sertkaya H, Şakar M. Buzağılarda tiletamin-zolazepam-xylazin ve ketaminxylazin anestezisi. Turk J Vet Amin Sci 2003; 27: 775-9.

Topal A. Kedilerde tiletamin/zolazepam ve xylazine/ ketamin anestezisinin karşılaştırılması. Kafkas Üniv Vet Fak Derg 2000; 6 (1-2): 81-8.

Topal A. Veteriner Anestezi. Birinci Baskı. Bursa: Nobel\&Güneş, 2005; s. 47-64.

Yanmaz LE, Doğan E, Okumuş Z, Şenocak MG, Ersöz U, Okur S. Comparison of intranasal and intramuscular administration of zolazepam tiletamine combination in cats. Atatürk Üniversitesi Vet Bi Derg 2017; 12(2): 124-9.

Yaygıngül R, Belge A. The comparison of clinical and cardiopulmonary effects of xylazine, medetomidine and detomidine in dogs. Ankara Üniv Vet Fak Derg 2018; 65: 313-22.

Zlateva N. Marinov G. Effect of three anesthetic protocols on the haematological indices in cats during ovariohysterectomy. Medlnform (Sofia) 2015; 2: 184-93. 